\title{
Niche differentiation in Meta bourneti and $M$. menardi (Araneae, Tetragnathidae) with notes on the life history
}

\author{
Stefano Mammola* and Marco Isaia \\ University of Turin, Department of Life Science and Systems Biology, Via Accademia Albertina, 13, Torino, Italy
}

\begin{abstract}
Meta menardi and $M$. bourneti are two species of spiders inhabiting caves and other subterranean habitats. The occurrence of both species within the same cave has never been proved convincingly and several authors hypothesized a complete niche differentiation mainly based on microclimatic conditions. In order to study the apparent niche differentiation of the two species, we studied several populations of $M$. menardi and M. bourneti occurring in six caves in the Western Italian Alps (NW Italy). A series of squared plots were monitored monthly from March 2012 to February 2013. At each survey, we counted individuals and we collected the main environmental variables at each plot, namely distance from cave entrance, structural typology (wall, floor, or ceiling), light intensity, wind speed and counts of potential prey. Moreover, temperature and relative humidity were continuously logged in each cave. We run several statistical models (GLMMs) in order to relate the counts of individuals to the environmental parameters. The distance from the cave entrance, structural typology and prey availability resulted most important factors driving the abundance of both species within the cave. On the other hand, despite life cycles appeared very similar, the two species seems to exhibit different tolerance to the microclimatic variations within the cave, which emerged as the main factors determining the differentiation of their niche. At least in our study area, $M$. bourneti tolerates broad microclimatic fluctuations and is potentially able to colonize a wide variety of caves. On the other hand, when the climatic conditions in a cave are suitable for M. menardi (narrow ranges of relatively low temperature and high humidity), M. bourneti is excluded.
\end{abstract}

Keywords: $\quad$ cave dwelling spider; conditional differentiation; ecological niche; GLMMs; western Italian Alps Received 27 May 2014; Revised 20 July 2014; Accepted 24 July 2014

Citation: Mammola S. and Isaia M., 2014. Niche differentiation in Meta bourneti and M. menardi (Araneae, Tetragnathidae) with notes on the life history. International Journal of Speleology, 43 (3), 343353, Tampa, FL (USA), ISSN 0392-6672 http://dx.doi.org/10.5038/1827-806X.43.3.11

\section{INTRODUCTION}

The genus Meta C.L. Koch (Araneae, Tetragnathidae) is represented worldwide by 34 species (Platnick, 2014). In Europe Meta menardi (Latreille) and $M$. bourneti Simon are reported (Nentwig et al., 2014). Both are medium size spiders, preferably found in the twilight zone of caves and other subterranean habitats such as cellars, mines, railway tunnels, hollow trees (Smithers, 2005a, 2005b; Nentwig et al., 2014) and stony debris (Růžička, 1990, 1999; Rưžička \& Klimeš, 2005). In order to encourage the study of the hypogean aranean fauna, $M$. menardi was recently designated both as Cave Animal of the Year in Germany and European Spider of the Year for 2012 (Hörweg et al., 2011). Regarding M. menardi, a wide range of studies focusing on the diet (e.g. Pötzsch, 1966; Eckert \& Moritz, 1992; Chapman, 1993; Novak, 2005; Smithers, 1996, 2004, 2005a; Novak et al.,
2010; Fritzén \& Koponen, 2011) and on observations of single prey items (Casale, 1988; Pastorelli \& Laghi, 2006; Harper, 2010) have been published. Moreover, Smithers (2005b) published a tentative life history for the United Kingdom. Spatial competition (Bourne, 1976; Bourne, 1977) and niche partitioning (Novak et al., 2010) between M. menardi and Metellina merianae (Araneae, Tetragnathidae) have been studied. On the contrary, to our knowledge the biology of $M$. bourneti is almost unknown. The only specific contribution on this species focuses on spermatogenesis (Boissin, 1973). In his wide contribution on Italian cave dwelling spiders Brignoli (1971) hypothesized that $M$. bourneti is more related to the underground environment than M. menardi. However, the biology and the ecology of the two species is apparently very similar (Gasparo \& Thaler, 2000): the size of adult spiders is comparable (Nentwig et al., 2014) and they build similar planar orb-webs with an open hub (Levi, 1980). Both species 
spin a 2-3 cm drop-shaped cocoon that is laid in the vicinity of the cave entrance. Both species may hunt both in web and actively on the walls (Eckert \& Moritz, 1992; Smithers, 1996, 2004, 2005a; Vadell, 2003). At least in Devon (UK), $M$. menardi generally lays the cocoon between June and August (Smithers, 2005b). After hatching (September - December), the spiderlings remain inside the cocoon until the first molt (Tercafs, 1972; Smithers, 2005b), feeding on the yolk (Foelix, 1996). After leaving the cocoon, the spiderlings move towards the cave entrance (Tercafs, 1972; Smithers \& Smith, 1998; Smithers, 2005b) and disperse via ballooning outside the cave (epigean ecophase). They remain outside the cave from six to eight weeks; afterwards they become photophobic and search for other suitable hypogean habitats (Smithers, 2005b). According to Lunghi et al. (2014), suitable habitats are presumably tracked by the air blowing from the entrances.

Several authors hypothesize that a different tolerance to temperature may be at the base of the apparent niche segregation of the two species (Brignoli, 1971; Ribera, 1978; Gasparo \& Thaler, 2000; Isaia et al., 2007). Based on a dataset of 20 subterranean sites in the Western Italian Alps, Isaia et al. (2007) pointed out a significant preference for cooler hypogean sites $\left(5-9^{\circ} \mathrm{C}\right)$ for $M$. menardi and for warmer sites (above $9^{\circ} \mathrm{C}$ ) for $M$. bourneti. The preference for warmer caves of $M$. bourneti seems also supported by its wide distribution in the Mediterranean (Nentwig et al., 2014). According to Platnick (2014), the distribution ranges from Europe to Georgia and North Africa. Viceversa, in Europe $M$. menardi reaches northern latitudes, up to the Scandinavian peninsula (Fritzén \& Koponen, 2011). Considering the partial overlap of the distribution ranges, Brignoli (1972) hypothesized that competition may occur. Data referring about the coexistence of the two species exists, but in most cases are based on misidentifications (Lana et al. 2002; Sella \& Lana, 2005; Arnò \& Lana, 2005; cited in Isaia et al., 2011). So far, the only unverified data about the coexistence are found in a cave in Canton Ticino, but are based on doubtful identifications of subadult spiders (cf. Dresco, 1960; Strinati, 1966; Dresco \& Hubert, 1978).

In the Western Italian Alps the presence of both Meta menardi and $M$. bourneti has been recorded (Arnò \& Lana, 2005; Isaia et al., 2011). The caves inhabited by $M$. bourneti are located at the mouth of two Alpine valleys, on south-facing slopes. Conversely, both valleys are inhabited by $M$. menardi on north-facing slopes (Isaia et al., 2011).

We carried out a scientific research aiming at i) characterizing the habitat of both Meta menardi and $M$. bourneti in order to identify the most important abiotic and biotic factors driving their relative position within the cave; ii) pointing out the environmental factors explaining the apparent niche segregation of the two species; iii) providing information about the life history of the two species from a regional perspective.
MATERIAL \& METHODS

\section{Study area}

In the Western Italian Alps (Piedmont, NW-Italy) Meta bourneti is recorded from three caves at the bottom of the Susa Valley (Province of Torino) and Stura-Gesso Valley (Province of Cuneo), on southfacing slopes (Isaia et al., 2011). Moreover, during recent speleological explorations, we recorded the presence of $M$. bourneti in two more small caves of Susa Valley. Caves inhabited by $M$. bourneti are included in so-called "xerothermic oasis", characterized by xerothermic sub-Mediterranean climate (Bagnouls \& Gaussen, 1957) within a general Alpine contest. The climatical peculiarity is testified by the presence of mediterranean vegetation, such as Quercus ilex and Juniperus oxycedrus in the Susa Valley (Sindaco et al., 2009) and xerophile grasslands in the Stura-Gesso Valley (Abbo et al., 1984). On the other hand, M. menardi occurs in caves on northfacing slopes (Fig. 1), characterized by hypomesaxeric climate (Bagnouls \& Gaussen, 1957).

In order to investigate the segregation of the two species in this area, for our study we choose three caves in Piedmont inhabited by $M$. bourneti and we selected three nearby caves inhabited by $M$. menardi. The distance between the caves inhabited by $M$. bourneti and $M$. menardi in the Susa Valley ranged from $1.9 \mathrm{~km}$ to $18 \mathrm{~km}$. In the Stura-Gesso Valley the two caves were located $6.7 \mathrm{~km}$ apart.

\section{Sampling design}

In the six study sites, eighty plots (squared areas of 1 x 1 meters, hereinafter squares; Table 1) were randomly placed inside the cave within $40 \mathrm{~m}$ from the entrance. Such distance was chosen according to the natural range of occurrence of Meta spiders, derived from previous observations within the sites (Isaia et al., 2011). Squares were distributed between the entrance zone (from 300 to $0.1 \mathrm{~lx}$ ), the sub-twilight zone (from 0.1 to $0.01 \mathrm{~lx}$ ) and the inner part of the cave (from 0.01 to $01 \mathrm{x}$ ). The distance from the cave entrance (DE) of each square was measured at the first survey. Since caves are structurally heterogeneous, we placed the squares in three different structural typologies (TP): floors $(\mathrm{F})$, walls $(\mathrm{W})$ and roofs $(\mathrm{R})$. The height of the squares varied between 0 (floors), 0-3 (walls) and 2-3 (roofs) meters from the ground.

Field investigations took place monthly from March 2012 to February 2013 (12 total surveys). During each survey, we counted the number of adult males, females, immature spiders, spiderlings and cocoons occurring at each square. In particular, according to Pennington (1979) we considered spiderlings immatures below the third instar, which were less than $5 \mathrm{~mm}$ in length and showed a well-defined white abdominal pattern. We considered as immature individuals the $4^{\text {th }}, 5^{\text {th }}$, and $6^{\text {th }}$ instars, while we considered adults sexually mature individuals $\left(7^{\text {th }}\right.$ instar). Moreover, we also recorded the presence of other arthropods occurring at each square. Whenever possible, we identified arthropods at the species level. On the base of available data in literature, 


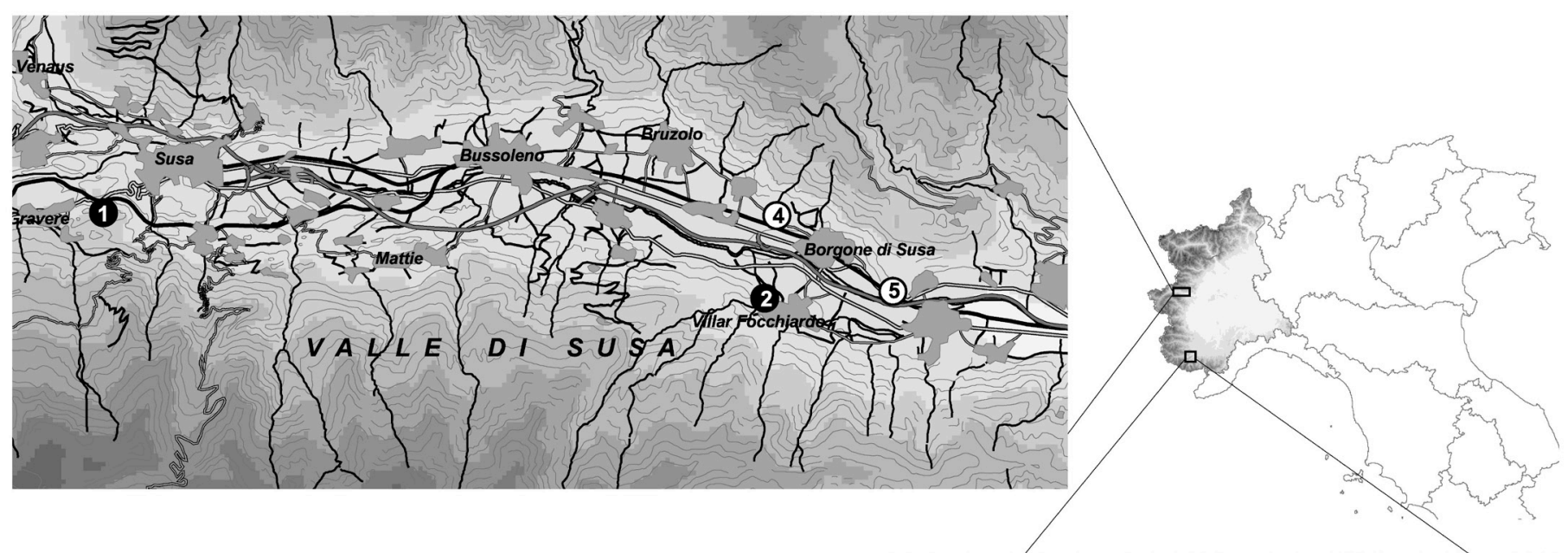

\section{Meta bourneti \\ Meta menardi}

1. $1597 \mathrm{Pi} / \mathrm{TO}$ - Balma Fumarella

2. Art. Pi/TO - Cave di Marra

3. $1002 \mathrm{Pi} / \mathrm{CN}$ - Grotta del Bandito

4. $1576 \mathrm{Pi} / \mathrm{TO}$ - Grotta A di Maometto

5. $1615 \mathrm{Pi} / \mathrm{TO} \& 1616 \mathrm{Pi} / \mathrm{TO}$ - Grotte della Testa di Napoleone

6. $1102 \mathrm{Pi} / \mathrm{CN}$ - Buco dell'Aria Calda

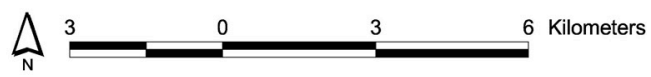

Fig. 1. Map of the study area.

the following arthropods were considered potential prey (PR): Orthoptera (Novak, 2005), Coleoptera (e.g. Pötzsch 1966, Casale, 1988; Chapman, 1993; Smithers, 1996, 2005a), Lepidoptera (Smithers, 2005), Diptera (Novak, 2005; Smithers, 2005a, Fritzén \& Koponen, 2011), Myriapods (Eckert \& Moritz, 1992; Chapmann, 1993; Smithers, 1996, 2004, 2005a; Harper, 2000; Novak, 2005; Pendleton and Pendleton, 2010), Araneae (Pötzsch 1966; Eckert \& Moritz, 1992; Smithers, 1996, 2005a; Novak, 2005), Gastropoda (cf. Nyffler \& Symondson, 2001) and Speleomantes (Amphibia, Plethodontidae) (Pastorelli \& Laghi, 2006).

At each square we measured (1) temperature of the flux of air (TW; ${ }^{\circ} \mathrm{C}$ ) and (2) wind speed (WS; m/s) by hot-wire probe AP $471 \mathrm{~S} 1$ (Delta OHM S.r.1., Padova, Italy) (accuracy of $\pm 0.4^{\circ} \mathrm{C}$ for the air temperature and $\pm 0.05 \mathrm{~m} / \mathrm{s}$ for the windspeed). We also measured (3) light intensity (L; lux) at each square by photometric probe LP 471 Phot (Delta OHM S.r.1.) (accuracy of $0.2 \% \pm 1$ digit). Both devices were connected with a portable meter DO9847 (Delta OHM S.r.1.). In the twilight zone of each site we placed a EL-USB-2+ (Lascar Electronics, Salisbury, United Kingdom)

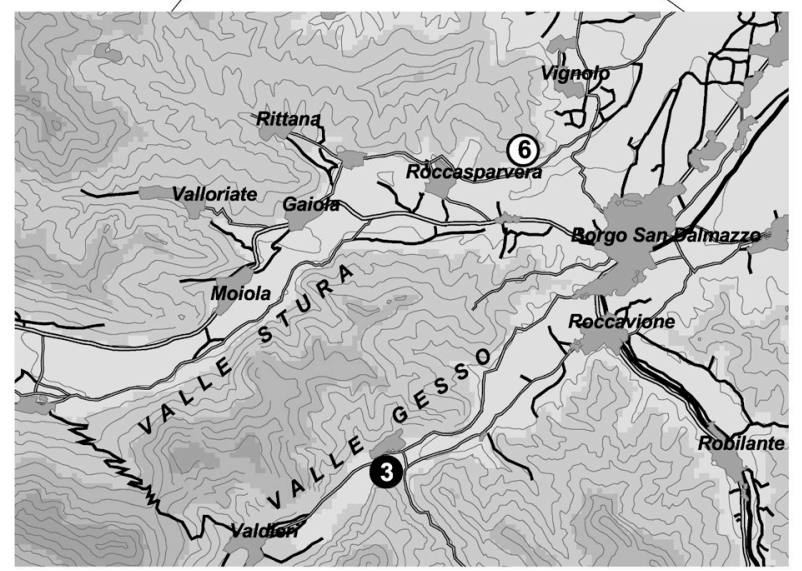

temperature and relative humidity datalogger programmed to record temperature $\left(\mathrm{T}^{\circ}\right)$ and relative humidity $(\mathrm{RH})$ every hour for the whole sampling period (accuracy of $\pm 0.5^{\circ} \mathrm{C}$ for temperature and $\pm 2.0 \%$ for relative humidity).

\section{Data analysis}

Habitat preference

For this analysis, we split the original dataset into two subsets, one referring to Meta bourneti and one to $M$. menardi. Data exploration was carried out following Zuur et al. (2010). We chose total counts of individuals (males + females + immature individuals) of $M$. menardi (MEN) and $M$. bourneti (BOU) as dependent variables in the models. The spiderlings were excluded from the analysis given the fact that they dwell in the cave for few months only (Smithers, 2005b). In order to take into account seasonality, we generated an additional, categorical variable (season: SEA). The variable "season" was made up of four different levels: winter (Wi), spring $(\mathrm{Sp})$, summer (Su) and autumn (Au). Since we pooled together the data collected from caves located in two

Table 1. List of the sites selected for the study and main descriptive parameters.

\begin{tabular}{|c|c|c|c|c|c|c|c|c|c|}
\hline Cave name & $\mathbf{N}^{\circ}$ Cadastre & Municipality & Valley & UTM coordinate & Length (m) & $\begin{array}{l}\text { Altitude (m) } \\
\text { (a.s.l.) }\end{array}$ & Geology & $\mathrm{N}^{\circ}$ of plots & Species \\
\hline Grotta del Bandito & $1002 \mathrm{Pi} / \mathrm{CN}$ & Roaschia & Stura & З2Т 3747164905527 & 336 & 714 & Limestone & 15 & Meta menardi \\
\hline Cave di Marra & Art. Pi/TO & Villar Focchiardo & Susa & З2Т 3603134997180 & $\sim 100$ & 430 & Gneiss & 15 & Meta menardi \\
\hline Balma Fumarella & $1597 \mathrm{Pi} / \mathrm{TO}$ & Gravere & Susa & З2Т 3453154999142 & 47 & 864 & Micaschist & 10 & Meta menardi \\
\hline Buco dell'Aria Calda & $1102 \mathrm{Pi} / \mathrm{CN}$ & Vignolo & Gesso & З2Т 3774064911834 & 140 & 815 & Calcschist & 16 & Meta bourneti \\
\hline Grotta A di Maometto & $1576 \mathrm{Pi} / \mathrm{TO}$ & San Didero & Susa & 32Т 3605704999097 & 7 & 421 & Gneiss & 6 & Meta bourneti \\
\hline Grotte di Napoleone & 1615 - $1616 \mathrm{Pi} / \mathrm{TO}$ & Borgone di Susa & Susa & 32Т 3632224997357 & $17-7$ & 442 & Serpentinite & $12+6$ & Meta bourneti \\
\hline
\end{tabular}


different valleys (Stura/Gesso and Susa), we included the variable valley $(\mathrm{V})$ as a covariate. We removed two outliers from the dependent variable "wind speed" (WS) and we $\log$-transformed $(\log \mathrm{X}+1)$ the variable "light intensity". Collinearity among the independent variables was evaluated by the Pearson correlation test $(r)$, and the choice of which covariates to drop was based on the variance inflation factors values (VIFs). The collinearity between continuous and categorical variables was graphically evaluated (boxplots). We related the subset of continuous (DE, WS, L, PR) and categorical (TP, SEA, V) explanatory variables selected after the data exploration to the dependent variables via generalized linear mixed models (GLMMs, Zuur et al., 2009b) in $\mathrm{R}$ environment ( $\mathrm{R}$ Development Core Team, 2013). The mixed procedure allowed us to include the temporal ("Square") and the spatial grouping variable ("Cave") as random factors in a twonested levels random-intercept structure (Square/ Cave). Such structure allowed us to deal with repeated observations and measurements of the same square (temporal dependence) and the clumped spatial distribution of the squares within the cave (spatial dependence). Instead, the categorical variable valley (V) was not included as random factor, being made up of only two levels (Susa and Stura-Gesso). The structure of the general model including all the non collinear variables of interest was:

\section{$\mathrm{y} \sim \mathrm{DE}+\mathrm{WS}+\mathrm{L}+\mathrm{PR}+\mathrm{TP}+\mathrm{SEA}+\mathrm{V}+(1 \mid$ Square $/$ Cave $)$}

Where $\mathrm{y}=$ counts of MEN or BOU. For the categorical variables TP, SEA and V, we selected "walls", "autumn" and "Stura-Gesso" as reference category (=baseline), respectively.

Once we fitted the general model, we carried out a backward model selection (backward elimination), deleting one by one the variables (if any) improving the model after their removal. We repeated this process until all remaining variables were statistically significant. For the dependent variables (counts) we assumed a Poisson distribution. We tested the final model for overdispersion and we validated it following Zuur et al. (2009b). Models were fitted via the lme4 (Bates et al., 2013) R package. The outcome of the models consisted of regression coefficients for the explanatory variables, whose significance was assessed via Wald tests (Dobson, 1990).

\section{Segregation between the two species}

In order to investigate the environmental factors explaining the segregation of the two species, we compared the climatic parameters of the caves inhabited by the two species, using GLMMs. The fixed part of the models was represented by the interaction between the sites (S) and the valleys (V) in which the sites are located. For this analysis, we used a dataset containing the annual series of temperature $\left(\mathrm{T}^{\circ}\right)$ and relative humidity $(\mathrm{RH})$ logged in each cave. Given that we pooled together the measurements from different caves, we included two single-term random factors in order to take into account the effect of the temporal repetition of the measurements ("record") and the spatial dependence of each sites in which we logged the climatic parameters ("cave"). Due to malfunction, two dataloggers located in Buco dell'Aria Calda and Cave di Marra did not provide valid records for the entire study, resulting in 10 and 8 valid series of data (out of 12 available for the other sites), respectively. Since temperature values during the year were normally distributed, we assumed a Gaussian distribution with an identity link function. On the contrary, relative humidity values were asymmetrically distributed (negative skewness). The relative humidity values were expressed as proportions within the range of $0-100 \%$, and were modeled assuming a Beta distribution (Cribrari-Neto \& Zeileis, 2010) via the glmmAMDB (Fournier et al., 2012) R package. The structure of the model was:

$$
\mathrm{y} \sim \mathrm{S} \text { x V + (1| Record })+(1 \mid \text { Cave })
$$

where $y=$ one of $\mathrm{T}^{\circ}$ or RH. For the interaction "S $\mathrm{x}$ V" we selected "M.m/Stura-Gesso" as the reference category (Meta menardi sites in the Stura-Gesso valley).

\section{RESULTS}

\section{Habitat preference of Meta menardi}

During the sampling period, we observed 513 individuals of Meta menardi, of which 428 where adults and juveniles and 85 were spiderlings. Over the year, juveniles represented two thirds of all specimens (66.7\%). Males were rare (11.45\%), with a sex ratio $(\mathrm{M} / \mathrm{F})$ of 0.52 . Males occurred mainly during the warm season, between July and September, while immature and female individuals occurred during the entire sampling period. Nevertheless, the number of juveniles was characterized by two peaks, in spring and autumn. We observed the cocoon deposition between August and October. The spiderlings occurred mainly between February and April. After emerging, the spiderlings remained in the nearby of the cocoon for 1-3 months and then disappeared from the cave. The phases of the life cycle are summarized in Figure 2.

We counted 856 potential preys occurring in the sampling squares belonging to 31 different taxa. In particular: dipterans (Insecta, Diptera; n=371 - 43.3\%), Dolychopoda ligustica (Orthoptera, Rhaphidophoridae; n=292 - 34.1\%), Amaurobius sp. (Araneae, Amaurobidae; $\mathrm{n}=38$ - 4.4\%), Tegenaria silvestris (Araneae, Agelenidae; $\mathrm{n}=34-3.9 \%$ ), Nesticus eremita (Araneae, Nesticidae; $\mathrm{n}=30-3,5 \%$ ), Metellina merianae (Araneae, Tetragnathidae; $\mathrm{n}=23$ - 2.6\%), Pimoa rupicola (Araneae, Pimoidae; $\mathrm{n}=12$ - 1.4\%). The remaining taxa were rare (each representing less than $1 \%$ of the total prey items) and mainly represented by nocturnal Lepidoptera (Triphosa spp. [Lepidoptera, Geometridae], Scolyopterix libatrix [Lepidoptera, Noctuidae]), Gastropods (Oxychilus spp. [Gastropoda, Oxychilidae]), Myriapods and Speleomantes strinatii (Amphibia, Plethodontidae). Dipterans, Dolichopoda ligustica, Scolyopterix libatrix and Myriapods where occasionally found wrapped in webs of $M$. menardi. 


\begin{tabular}{|r|l|l|}
\cline { 2 - 3 } \multicolumn{1}{c|}{} & Mar Apr May Jun Jul Aug Sep Oct Nov Dic Jen Feb \\
\hline Presence of adult females & \multicolumn{2}{|c|}{} \\
\hline Presence of adult males & \\
\hline Cocoon deposition & \\
\hline Hatching of spiderlings & \\
\hline Emigration of spiderlings & \\
\hline
\end{tabular}

$\square$ Meta menardi $\square$ Meta bourneti

Fig. 2. Summary of the main stages of the life cycle of Meta menardi and M. bourneti in the study area.

With respect to the analysis of the environmental parameters influencing the abundance of each species within the cave, Poisson models were fitted since the ratio between observed and theoretical variance approached the unit value assumed by the Poisson distribution. After model selection, according to the most appropriate model (Table 2) the total number of individuals was found to increase significantly inversely to distance from the entrance (within the range of occurrence of the species 1-40 m; DE: Estimate $\beta:-0.1308$, SE: $\left.0.0216, \quad p<0.01^{* *}\right)$ and positively with the increase in number of potential preys (PR: Estimates $\beta$ : 0.0390, SE: $\left.0.0113, \mathrm{p}<0.01^{* *}\right)$. The total number of individuals was also found to decrease in the squares placed on the floor with respect to the reference category (wall) (TP_R: Estimate $\beta:-1.8090$, $\mathrm{SE}: 0.6012, \mathrm{p}<0.01^{* *}$ (Fig. 3a).

\section{Habitat preference of Meta bourneti}

During the sampling period, we observed 464 individuals of Meta bourneti, of which 331 were adults

Table 2. Estimated Poisson regression parameters according to GLMMs. The final model structures are reported. MEN = counts of males, females and juveniles of Meta menardi; $\mathrm{BOU}=$ counts of males, females and juveniles of $M$. bourneti; $D E=$ distance from the cave entrance $(\mathrm{m})$; $\mathrm{PR}=$ counts of potential prey; SEA = season (categorical variable: $\mathrm{Au}=$ autumn; $\mathrm{Wi}=$ winter; $\mathrm{Sp}=$ spring; $\mathrm{Su}=$ summer); TP = structural type of the square (categorical variable: $\mathrm{W}=$ wall; $\mathrm{R}=$ roof; $\mathrm{F}=$ floor). Significance codes: ${ }^{*} 0.05 ;{ }^{* *} 0.01$.

\begin{tabular}{|c|c|c|c|c|c|}
\hline Final model & Variables & Estimate $\beta$ & SE & z & $\mathbf{p}$ \\
\hline \multicolumn{6}{|c|}{ MEN $\sim D E+P R+T P+(1 \mid$ Square/Cave $)$} \\
\hline \multirow[t]{5}{*}{ Overdispersion parameter $=0.96$} & Intercept & 0.3833 & 0.3206 & - & - \\
\hline & $\mathrm{DE}$ & -0.1308 & 0.0216 & -6.03 & $0.00^{* *}$ \\
\hline & PR & 0.0390 & 0.0113 & 3.44 & $0.00^{* *}$ \\
\hline & $T P(R)$ & 0.4357 & 0.3478 & 1.25 & 0.21 \\
\hline & $\operatorname{TP}(F)$ & -1.8090 & 0.6012 & -3.00 & $0.00^{* *}$ \\
\hline \multicolumn{6}{|c|}{$B O U \sim D E+P R+S E A+T P+(1 \mid$ Square/Cave $)$} \\
\hline \multirow[t]{8}{*}{ Overdispersion parameter $=0.90$} & Intercept & 0.5358 & 0.2795 & - & - \\
\hline & DE & -0.1867 & 0.0419 & -4.45 & $0.00^{* *}$ \\
\hline & PR & 0.0384 & 0.0208 & 1.84 & $0.06(*)$ \\
\hline & $\operatorname{SEA}(\mathrm{Sp})$ & 0.1239 & 0.1455 & 0.85 & 0.39 \\
\hline & SEA (Su) & -0.5621 & 0.1743 & -3.22 & $0.00^{* *}$ \\
\hline & SEA (Wi ) & -0.0766 & 0.1528 & -0.50 & 0.61 \\
\hline & $T P(R)$ & -0.9557 & 0.4454 & -2.14 & 0.03 * \\
\hline & $\operatorname{TP}(F)$ & -1.2625 & 0.4541 & -2.78 & $0.00^{* *}$ \\
\hline
\end{tabular}

and juveniles and 133 were spiderlings. Over the year, juveniles represented $51.7 \%$ of all specimens. Males were rare $(7 \%)$, with a sex ratio (M/F) of 0.16. Males occurred, in low abundances, from August to December, while female and juveniles were observed during the entire sampling period. Cocoons were laid between October and November. The spiderlings hatched from the eggsacs between January and February, and assembled in groups around the cocoons. After 1-2 months they disappeared from the cave (Fig. 2).

We counted 870 potential prey occurring in the sampling squares, belonging to 37 different taxa. In particular: dipterans ( $\mathrm{n}=365$ - 30.1\%), Dolychopoda ligustica ( $\mathrm{n}=126-14.3 \%)$, Nesticus eremita $(\mathrm{n}=120$ $13.6 \%)$, Tegenaria silvestris ( $\mathrm{n}=64-7.2 \%)$, Oxychilus sp. ( $\mathrm{n}=57-5.3 \%)$, Glomeris sp. (Diplopoda, Glomeridae; $\mathrm{n}=57-5.3 \%)$, Metellina merianae $(\mathrm{n}=50-5 \%)$. The remaining taxa were rare (each representing less than $1 \%$ of the total prey items), and mainly represented by nocturnal Lepidoptera (Triphosa spp.), Gastropods

(Helix pomatia [Gastropoda, Helicidae], Limax subalpinus [Gastropoda, Helicidae]), spiders (Pholcus phalangioides [Araneae, Pholcidae], Leptoneta crypticola [Araneae, Leptonetidae], Pimoa rupicola) and Myriapods. The most represented arthropods found wrapped in webs of M. bourneti were Glomeris sp. (for which we also observed three predations), Metellina, Oxychilus and Euscorpius sp. (Scorpiones, Euscorpidae).

According to the most appropriate model explaining the habitat preference of Meta bourneti (Table 2), in the range of occurrence of the species the total number of individuals was found to increase significantly inversely to distance from the entrance (DE: Estimate $\beta$ : $-0.1867, \mathrm{SE}$ : $\left.0.0419, \mathrm{p}<0.01^{* *}\right)$ and positively with the increase of potential prey (PR: Estimates $\beta$ : 0.0384, SE: $\left.0.0208, p=0.06\left[{ }^{*}\right]\right)$, although this trend was weakly significant. Regarding the preference in term of structural typology, we found less individuals on roofs and floors with respect to the reference category (wall) (TP_R: Estimate $\beta$ : $-0.9557, \mathrm{SE}$ : $0.4454, p<0.03^{*}$; TP_F: Estimate $\beta:-1.2425$, SE: $\left.0.45411, \mathrm{p}<0.01^{* *}\right)$. Moreover, counts were lower during the summer season with respect to the 


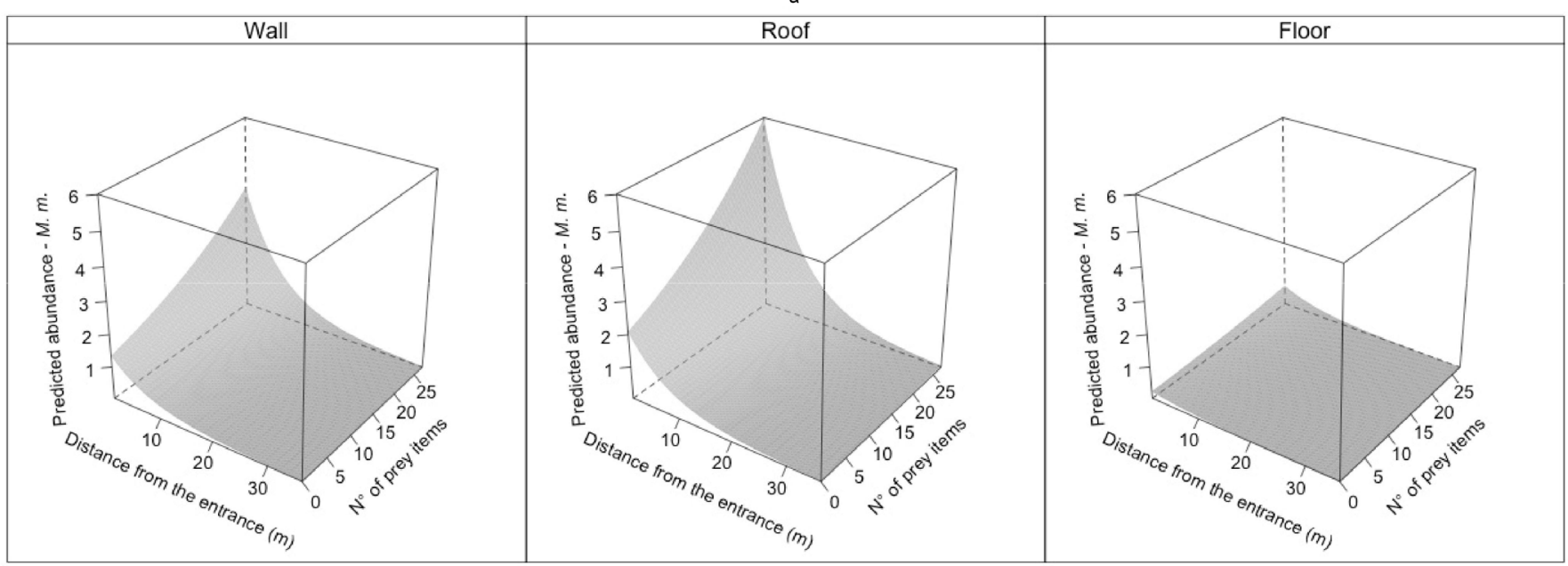

b

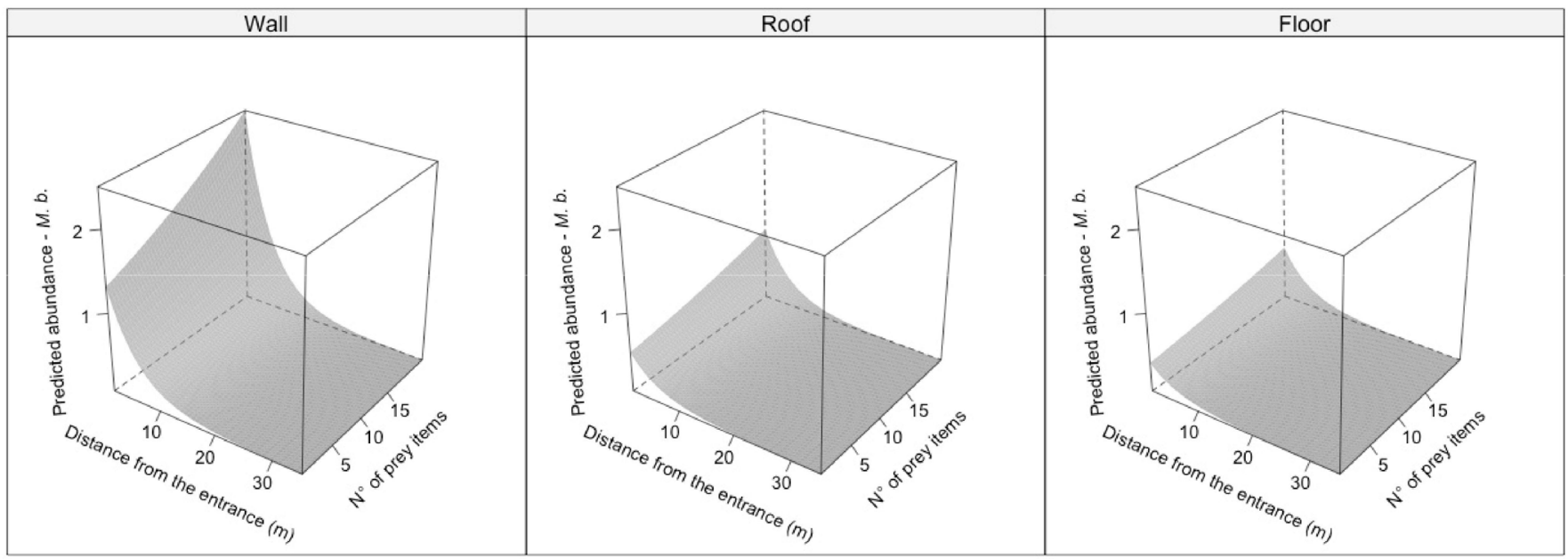

Fig. 3. Predicted abundances of a) Meta menardi (M. m.) and b) M. bourneti (M. b.) in relation to the distance from the cave entrance and the presence of potential prey items, by the factor typology of the square (wall, roof, floor) according to GLMMs. The predicted values for M. bourneti are obtained setting the season factor (SEA) equal to the baseline (Autumn).

reference category (Autumn) (SEA_Su: Estimate $\beta$ : $\left.-0.5621, \mathrm{SE}: 0.1743, \mathrm{p}<0.01^{* *}\right)$ (Fig. $\left.3 \mathrm{~b}\right)$.

\section{Comparison between sites inhabited by Meta menardi or $M$. bourneti}

From a climatic point of view, the yearly ranges of the parameters in two out of three sites inhabited by Meta menardi sites were similar (Cave di Marra: mean annual temperature $\pm \mathrm{SD}=9.63 \pm 1.29$; mean annual relative humidity (\%) $\pm \mathrm{SD}=98.23 \pm 1.99$; Grotta del Bandito: 9.74 $\pm 2.64 ; 99.42 \pm 0.58)$. The mean annual temperature in Balma Fumarella site was higher, with a broad variability during the year (10.45 \pm 4.29$)$. In all caves the relative humidity never dropped below $80 \%$. On the other hand, the four caves inhabited by $M$. bourneti were characterized by higher mean annual temperature and lower relative humidity (Buco dell'Aria Calda: mean annual temperature $\pm \mathrm{SD}=15.44 \pm 3.64$; mean annual relative humidity $\% \pm \mathrm{SD}=94.40 \pm 11.52$, Grotta A di Maometto: 11.58 \pm 4.84 ; 93.09 \pm 7.92 ,

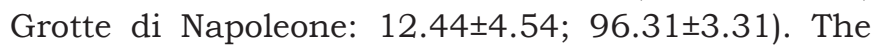
climatical differences between sites inhabited by the two species were confirmed statistically. In particular, the interaction ("Site $x$ Valley") was positive and significant for relative humidity (Estimate $\beta$ : 0.2949, SE: $0.1010, \mathrm{p}<0.01^{* *}$ ), with $M$. menardi sites showing higher median humidity over the year within the two valleys with respect to the baseline (sites of $M$. menardi in the Valle Stura/Gesso) (Fig. 4a). The same interaction was also significant for the temperature model (Estimates $\beta$ : -2.4957, SE: 1.0190, $\mathrm{p}<0.05 *$ ), with the caves inhabited by $M$. menardi with lower median temperature values with respect to the reference category (Fig. 4b).

\section{DISCUSSION}

\section{Habitat preference within the cave}

Besides the preference for caves and other subterranean habitats like cellars and mines, little is known about the ecological requirements of $M$. bourneti. The ecology of $M$. menardi, instead, is documented in Bourne $(1976$, 1977), Smithers (2005a, 2005b), Ružička \& Klimeš (2005) and Novak et al. (2010).

On the base of personal observations, Gasparo \& Thaler (2000) pointed out that the ecology of the two species should be somehow similar. Our analysis of the abiotic and biotic factors driving the abundance of both species within the cave seems to confirm this hypothesis, showing for both species a clear preference for the cave walls closer to the entrance, with higher prey availability. Despite the fact that $M$. menardi has been occasionally recorded in the 
a

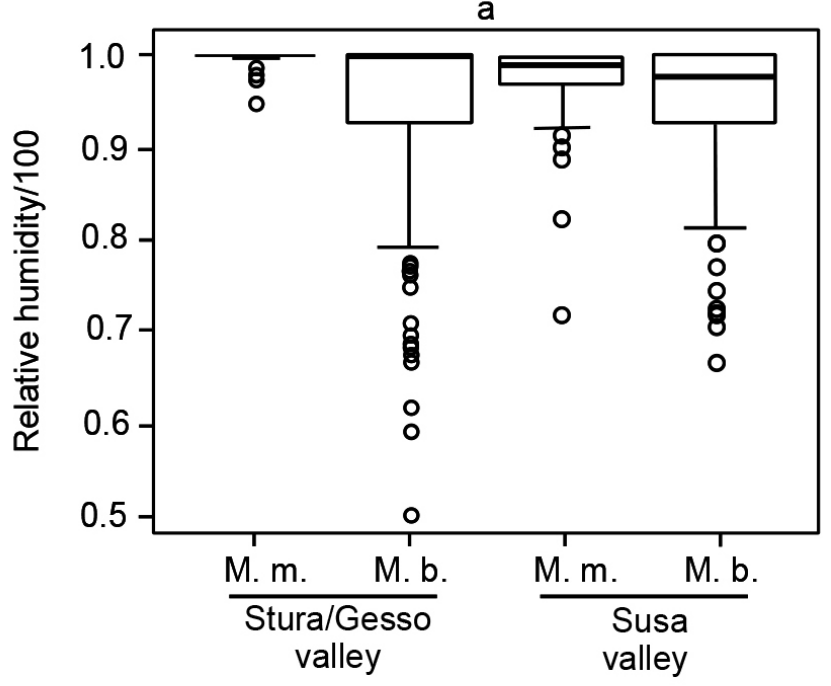

b

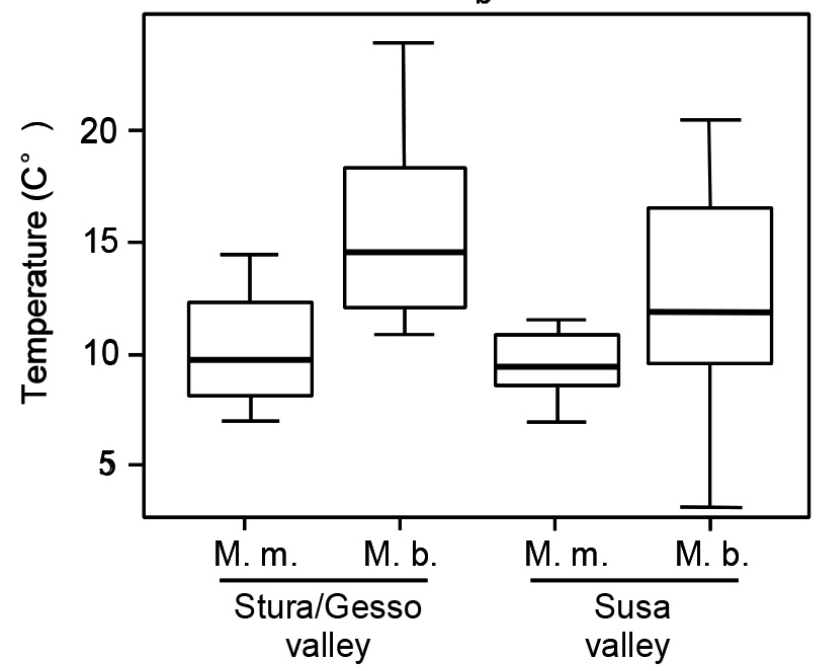

- Median

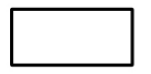

$25-75 \%$

$\mp$ Non-outlier range o Outlier

Fig. 4. Boxplot showing the difference in term of a) moisture and b) temperature between cavities inhabited by Meta menardi ( $M$. $m$.) and by M. bourneti (M. b.) in the two valleys (Stura/Gesso and Susa). Outliers are defined as values outside the interquartile range.

deep zone (Väisänen, 1983; Smithers, 1995), we statistically confirm that both species prefer the cave entrance. A similar preference was observed for $M$. menardi in various subterranean environments (Bourne, 1976; Smithers, 1995; Gasparo \& Thaler, 2000; Lana, 2001, among others). In a recent study set in Slovenia, M. menardi was reported from 0 to $69 \mathrm{~m}$ up into the deep zone (Novak et al., 2012). In our study area the number of spiders of both species drastically decreased after 10-12 $\mathrm{m}$ from the cave entrance. A possible explanation for this is found in the reproductive strategy of both species. Females always lay the cocoon in the twilight zone (indeed we never recorded egg sacs over $10 \mathrm{~m}$ into the interior), watching over it until the hatching (Hörweg et al., 2011). Moreover, the twilight zone is also a favorable position for the spiderlings. As Smithers \& Smith (1998) demonstrated, spiderlings emerging from cocoons display a positive phototaxis while adults are repulsed by light. Moving towards light, the spiderlings are able to leave the cave and disperse by ballooning (epigean eco-phase; Smithers, 2005b).

Both species seem also able to exploit the high availability of prey that characterize the cave entrance zone. It is generally accepted that the availability, abundance and typology of food resources play a fundamental role in hypogean oligotrophic environments (Culver, 1982). The link between the twilight zone and the external world (epigean/ hypogean ecotone) enhances the movement of occasional prey into the cave (Prous et al., 2004; Tobin et al., 2013). Deeper inside, caves may host troglobite and troglophile species (sensu Sket, 2008), that may occasionally represent prey items for Meta spiders (Smithers, 2005a; but see Slay et al., 2009). On the contrary, in the vicinity of the cave entrance occasional prey from outside are potentially available throughout the year (Prous et al., 2004; Smithers, 2005a; Novak et al., 2010; Tobin et al., 2013). These prey items can be efficiently exploited (Smithers, 1996, 2005a) thanks to the combined way of hunting in webs and on walls that typify both M. menardi (Eckert \& Moritz, 1992; Smithers, 1996, 2004, 2005a) and M. bourneti (Vadell, 2003). A similar relation between spiders and large aggregations of prey has also been observed in North America for M. ovalis (Yodel et al., 2010). Furthermore Ficetola et al. (2012) proposed the abundance of $M$. menardi to be a proxy of the availability of prey items in the cave environment.

Regarding the structural typology of the squares, $M$. menardi showed a clear preference for walls and roofs, while floors were avoided. A similar trend was reported by Bourne $(1976 ; 1977)$. M. bourneti also preferred walls, but, on the contrary, counts of $M$. bourneti were lower on roofs and floors. It is likely that, at least in our study, floors were not suitable in terms of prey availability. Moreover Eckert \& Moritz (1992) and Smithers (1996) noticed that $M$. menardi attaches the web radii directly to the walls. In this sense, lacking three-dimensionality for building the orb-web, floors are generally avoided. On the other hand, $M$. bourneti seems able to colonize floors occasionally (Fig. 3a, 3b). According to our results, cave roofs seem unfavorable to $M$. bourneti especially during the warm season. This effect can be related to the warming of the higher air parcels, "trapped" in the upper parts of galleries during the warm season (Badino, 2004, 2010).

At the same time, we observed a significant effect of the seasonality for $M$. bourneti. During summer, we observed very few individuals, while the abundance of spiders was almost constant during the rest of the year. It seems likely that the summer drop of counts of $M$. bourneti is related to the increase of the daily temperature occurring in the vicinity of the entrance (indeed during the summer season, temperature at Buco dell'Aria Calda got over $20^{\circ} \mathrm{C}$ ). At the same time, we observed several individuals deeper inside the cave, out of the range of our sampling squares, where the environment is buffered from the climatical variability of the outside. Similarly, Gasparo \& Thaler (2000) 
observed for $M$. menardi some seasonal migrations of single individuals deeper inside the cave. Spatial migrations to face seasonal microclimate changes are also reported in Růžička \& Klimeš (2005) and Lunghi et al. (2014). Despite the lower number of observations, we hypothesize a similar behavior for $M$. bourneti. In order to face the climatical fluctuations of the twilight zone in summer, spiders may also move into the cooler deeper fissures of the cave (more stable in terms of temperature fluctuation; Badino, 2010) resulting in a lower probability of being observed.

\section{Niche differentiation}

As previously discussed, factors affecting the abundance of the two species within the cave seem to be very similar. Still the question remains why the two species have never been found in syntopy (Brignoli, 1972; Brignoli, 1978; Ribera, 1978; Gasparo \& Thaler, 2000; Milner, 2013). Thanks to ballooning, Meta spiders could virtually colonize hypogean habitats that are far apart from each other. In both Susa and Stura/Gesso valleys, caves inhabited by Meta menardi and $M$. bourneti are very close to each others, but we never observed the species inhabiting the same cave.

Our study seems to confirm that the main factor inhibiting the co-occurrence of the two species is indeed related to the cave microclimate. More specifically, $M$. bourneti seems to tolerate a higher microclimatic variability, while $M$. menardi seems to be adapted to narrow ranges of cooler temperature and higher relative humidity. Consequently, we argue that $M$. menardi is more stenoecious than $M$. bourneti. Considering the preferred ranges of temperatures and relative humidity, the cooccurrence seems possible in a narrow window of values (Fig. 5). Given the same habitat requirements (i.e. selection of areas nearby the entrance with higher prey availability), the competition between $M$. menardi and $M$. bourneti hypothesized by Brignoli (1972) seems to occur: in caves that are suitable for both species (temperature $10-12.6^{\circ} \mathrm{C}$ and relative humidity $97.5-100 \%$; Fig. 4a, 4b, 5), M. bourneti is

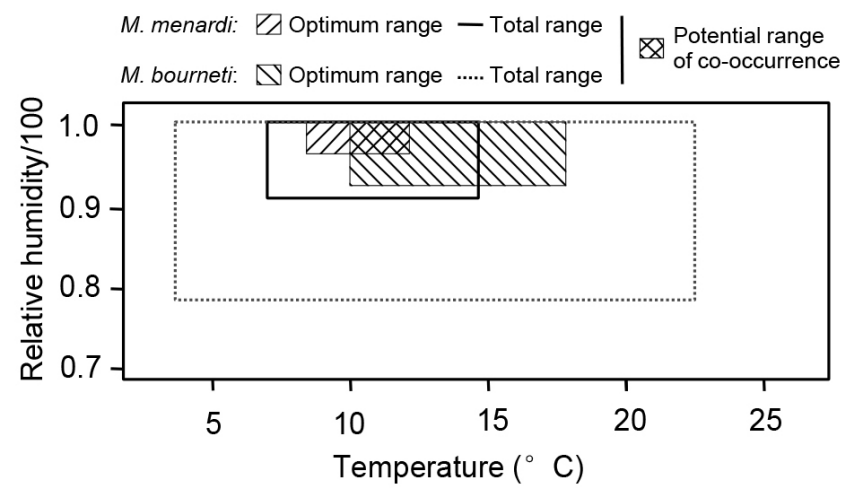

Fig. 5. Diagram showing the range of temperature and relativity humidity in which Meta menardi and $M$. bourneti occurs in the investigated caves. The optimum range of occurrence of the two species is obtained from the lower and the upper quartiles of the boxplots reported in Fig. 4, while the total range goes from the minimum to the maximum value (outlier excluded). The potential range of co-occurrence is obtained by the overlapping of the two optimum ranges of occurrence. apparently excluded. A conditional differentiation (Amarasekare, 2003) is therefore observed, with one species ( $M$. menardi) more competitive in one set of environmental condition (narrow ranges of cooler temperature and higher relative humidity). In this scenario, the presence of $M$. bourneti in Western Italian Alps, where most caves are cool and humid, represents a faunistic peculiarity, being apparently limited to few caves where the conditions are unfavorable to $M$. menardi. On the contrary, in areas with an unsuitable climate for $M$. menardi, $M$. bourneti becomes the best competitor within the cave. Such argumentation seem to explain why $M$. bourneti gradually becomes more frequent and $M$. menardi rare with decreasing latitude, as observed by Brignoli (1971) in Italy. Similarly, in northeastern Spain $M$. bourneti is preferably found in caves below 900 meters a.s.1., while M. menardi is found mainly above $900 \mathrm{~m}$ a.s.1., in the Pyrenean region (Ribera, 1978).

Milner (2013) recently reported an interesting distributional scenario for the London area, where the records are clearly divided into those north $(M$. bourneti), and those south (M. menardi) of the river Thames, apparently very similar from a climatic perspective. In view of our result, it seems likely that, due its larger ecological plasticity (cf. also Tatole, 2005), M. bourneti should have colonize all suitable sites not previously occupied by $M$. menardi. According to such plasticity, the hypothesis of Browning \& Tams (1944) and Gasparo \& Thaler (2000) about the importation of $M$. bourneti in the UK seem convincingly supported.

\section{Notes on the life history}

Climatic and microclimatic differences also represent an important factor explaining the seasonal shifts of the phenology of the two species (cf. Fig. 2). In particular, we detected a shift in the time of laying and hatching of the egg sac. While Meta menardi laid the cocoon earlier in the season (August-October versus October-November for $M$. bourneti), the spiderlings of $M$. bourneti hatched and dispersed earlier (January-February versus February-April). The earlier emigration of $M$. bourneti from the cave can be related to the shorter duration of the cold season in the south-facing slopes.

On the base of our observations and in accordance with literature (Tercafs, 1972; Pennington, 1979; Smithers \& Smith, 1998; Smithers, 2005; Hörweg et al., 2011), we report the life cycle of $M$. menardi and $M$. bourneti in Fig. 6. However, further studies focusing on the life cycle of $M$. bourneti are needed in order to confirm the epigean ecophase of this species.

\section{CONCLUSIONS}

Meta menardi and $M$. bourneti share most of their ecological requirements and show similar life cycles. According to our results, cave walls closer to the entrance with high prey availability provide 


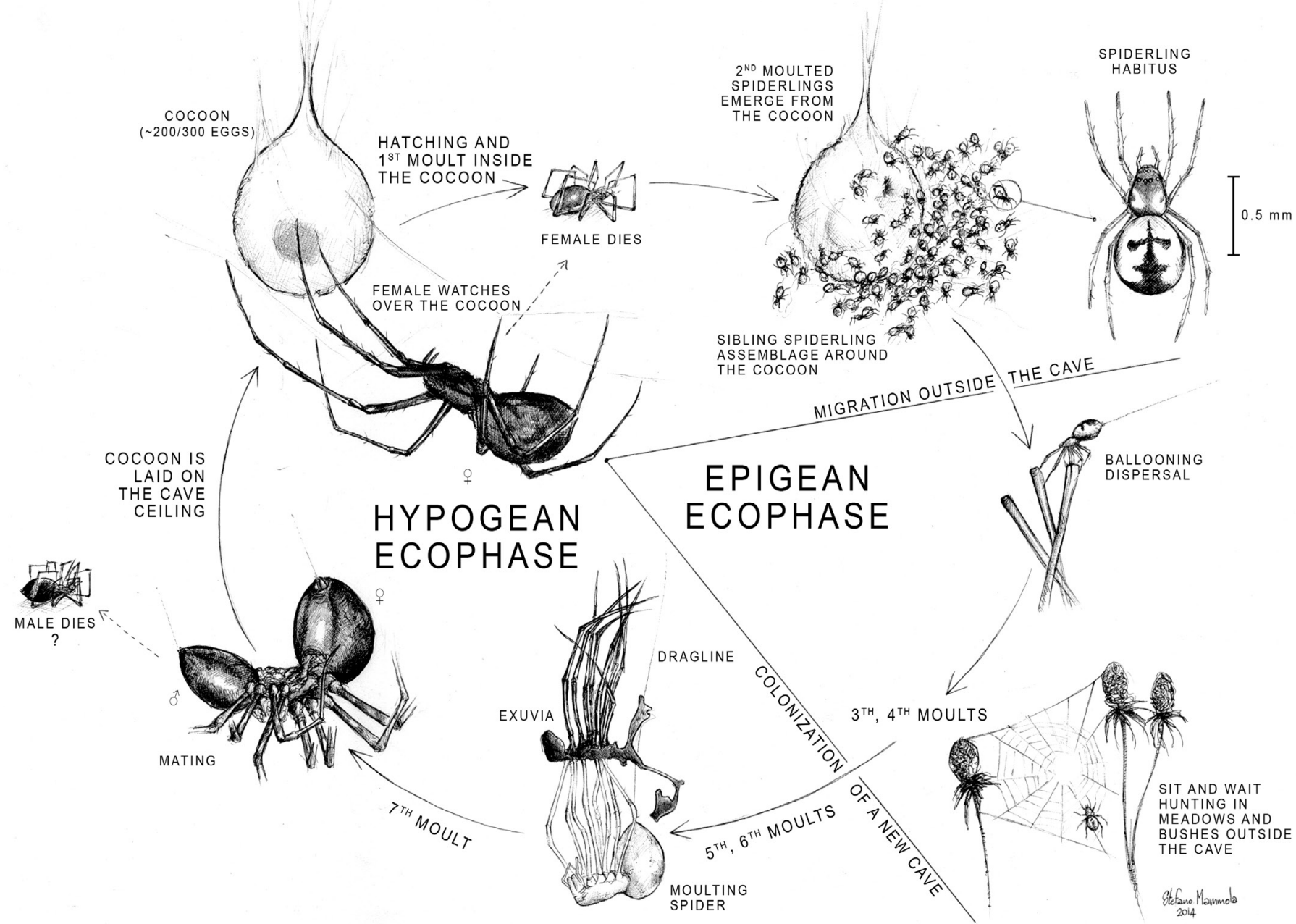

Fig. 6. The life cycle of Meta menardi and M. bourneti [lllustration by Stefano Mammola].

the most suitable conditions for both species within the cave. On the other hand the tolerance to fluctuations of temperature and relative humidity, emerged as one of the main factors explaining the partitioning of the niche through conditional differentiation. The co-occurrence of the two species seems possible in a narrow climatic range, in which $M$. menardi apparently excludes $M$. bourneti. This seems to confirm that competition between the two species occurs, as previously hypothesized on empirical base by several biospeleogist and arachnologist from the 1970s onward.

\section{ACKNOWLEDGEMENTS}

This study was part of the CaveLab project "From microclimate to climate change: caves as laboratories for the study of the effects of temperature on ecosystems and biodiversity", funded by the University of Turin and Compagnia di San Paolo. We are indebted to Peter Smithers and two anonymous referees for their suggestions and improvement to the manuscript. We would like to thank Enrico Lana for showing us the small caves populated by Meta bourneti in Susa Valley and Fulvio Gasparo for all valuable suggestions. Special thanks goes to all friends and colleagues involved in the samplings: Mauro Paschetta, Elena Piano Jr. and Sr., Martina Dalle, Davide Giuliano, Martino Adamo, and Giulia (II) Musso.

\section{REFERENCES}

Abbo E., Calleris V., Castellino S., Elia E., Manzone P. \& Peano G., 1984 - Il Buco dell'Aria Calda. Mondo Ipogeo, annuario del G.S.A.M. C.A.I. Cuneo, 11: 43-47.

Amarasekare P., 2003 - Competitive coexistence in spatially structured environments: a synthesis. Ecology Letters, 6: 1109-1122.

http://dx.doi.org/10.1046/j.1461-0248.2003.00530.x

Arnò C. \& Lana E., 2005 - Ragni cavernicoli del Piemonte e della Valle d'Aosta. Associazione Gruppi Speleologici Piemontesi, Regione Piemonte, Ed. "La Grafica Nuova", Torino, $265 \mathrm{p}$.

Badino G., 2004 - Clouds in caves. Speleogenesis and Evolution of Karst Aquifers, 2: 1-8.

Badino G., 2010 - Underground meteorology. What's the weather underground? Acta Carsologica, 39 (3): 427-448.

Bagnouls F. \& Gaussen H., 1957 - Les climats biologique et leur classification. Annales de Géographie, 66: 194220. http://dx.doi.org/10.3406/geo.1957.18273

Bates D., Maechler M., Bolker B. \& Walker S., 2013 lme4: Linear mixed-effects models using Eigen and S4. $\mathrm{R}$ package version 1.0-5, http://CRAN.R-project.org/ package $=1 \mathrm{me} 4$

Boissin L., 1973 - Étude ultrastructurale de la spermiogenèse de Meta bourneti Simon (Arachnides, Aranéides, Metinae). Comptes Rendus deuxième de la Réunion Arachnologique d'Expression Française: 7-22.

Bourne J.D., 1976 - Notes préliminaires sur la distribution spatiale du Meta menardi, Triphosa dubitata, Triphosa sabaudiata, Nelima aurantiaca et Culex pipiens au sain d'un écosystéme cavernicole (Grotte de Scierce: Mte. Savoie). International Journal of Speleology, 8: 253-267. 
Bourne J.D., 1977 - Mise en evidence de groupements temporaires de la faune pariétale dans un tunnel artificiel en fonction de l'humidité et des mouvements d'air. Revue Suisse de Zoologie, 84: 527-539.

Brignoli P.M., 1971 - Note su ragni cavernicoli italiani (Araneae). Fragmenta entomologica, 7 (3): 129-229.

Brignoli P.M., 1972 - Catalogo dei ragni cavernicoli italiani. Quaderni di Speleologia del Circolo Speleologico Romano, 20: 1-211.

Brignoli P.M., 1978 - Ragnid'Italia XXXII. Specie cavernicole di Sicilia (Araneae). Animalia, 5 (1/3): 273-286.

Browning E. \& Tams W.H.T., 1944 - On the occurrence in Suffolk of a Western Mediterranean cavernicolous spider, Meta bourneti Simon (Araneae: Argyopidae). Proceedings of the Linnean Society of London, 156: 95-96. http://dx.doi.org/10.1111/j.1095-8312.1944.tb00378.x

Casale A., 1988 - Revisione degli Sphodrina (Coleoptera, Carabidae, Sphodrini). Monografie del Museo di Scienze Naturali di Torino, Torino, 1024 p.

Chapman P., 1993 - Cave and cave life. Harper Collins, London, $224 \mathrm{p}$.

Cribari-Neto F. \& Zeileis A., 2010 - Beta Regression in R. Journal of Statistical Software, 34 (2): 1-24. http://www.jstatsoft.org/v34/i02/

Culver D., 1982 - Cave Life. Evolution and Ecology. Harvard University Press, Cambridge, 189 p. http://dx.doi.org/10.4159/harvard.9780674330214

Dresco E., 1960 - Catalogue raisonné des araignées et des opilions des grottes du canton du Tessin (Suisse). Annales de Spéléologie 14(3-4): 359-390.

Dresco E. \& Hubert M., 1978 - Araneae Speluncarum Helvetiae I. Revue Suisse de Zoologie, 85 (1): 157-165.

Dobson A.J., 1990 - An introduction to generalized linear models. Chapman and Hall, New York, 174 p.

Ecker R. \& Moritz M., 1992 - Meta menardi (Latr.) and Meta merianae (Scop.): On the biology and habitat of the commonest spiders in caves of the Harz, the Kyffhauser, Thuringa and the Zittau mountains. Mitteilungen aus dem Zoologischen Museum Berlin, 68 (2): 345-350.

Ficetola F.G., Pennati R. \& Manenti R., 2012 - Do cave salamanders occur randomly in cavities? An analysis with Hydromantes strinatii. Amphibia-Reptilia, 33: 251259. http://dx.doi.org/10.1163/156853812X638536

Fritzén N.R. \& Koponen S., 2011 - The cave spider Meta menardi (Araneae, Tetragnathidae) occurrence in Finland and notes on its biology. Memoranda Societatis pro Fauna et Flora Fennica, 87: 80-86.

Foelix R.F., 1996 - Biology of Spiders (second edition). Oxford University Press, New York, 330 p.

Fournier D.A., Skaug H.J., Ancheta J., Ianelli J., Magnusson A., Maunder M., Nielsen A. \& Sibert J., 2012 - AD Model Builder: using automatic differentiation for statistical inference of highly parameterized complex nonlinear models. Optimization Methods and Software, 27: 233-249.

http://dx.doi.org/10.1080/10556788.2011.597854

Gasparo F. \& Thaler K., 2000 - I ragni cavernicoli del Venezia Giulia (Italia nord-orientale) (Arachnida, Araneae). Atti e Memorie della Commissione Grotte "E. Boegan", 37: 17-55.

Harper J., 2010 - Polydesmus angustus in web of Meta menardi in the Forest of Dean. Bulletin of the British Myriapod Group and Isopoda group, 24: 53-54.

Hörweg C., Blick T. \& Zaenker S., 2011 - Die Grosse Hoehlenspinne, Meta menardi (Araneae: Tetragnathidae), Spinne des Jahres 2012. The large cave spider Meta menardi (Latreille, 1804) Cave animal of the year and European spider of the year 2012. Mitteilungen des Verbandes der Deutschen Höhlen und Karstforscher, 57 (4): 108-109.
Isaia M., Paschetta M., Lana E., Pantini P., Schőnhofer A.L., Christian E. \& Badino G., 2011 - Subterranean arachnids of the Western Italian Alps (Arachnida: Araneae, Opiliones, Palpigradi, Pseudoscorpiones). Monografie XLVII, Museo Regionale di Scienze Naturali, Torino, $325 \mathrm{p}$.

Lana E. 2001 - Biospeleologia del Piemonte. Atlante fotografico sistematico. A.G.S.P., Regione Piemonte, ed. "La grafica nuova", Torino, 264 p.

Lana E., Giachino P.M. \& Casale A., 2002 - Attività biospeleologica 2001. Grotte, Bollettino del Gruppo Speleologico Piemontese, 137: 35-39.

Levi H.W., 1980 - The orb-weaver genus Mecynogea, the subfamily Metinae and the genera Pachygnatha, Glenognatha and Azilia of the subfamily Tetragnathinae north of Mexico (Araneae: Araneidae). Bulletin of the Museum of Comparative Zoology, 149: 1-74.

Lunghi E., Manenti R. \& Ficetola G.F., 2014 - Do cave features affect underground habitat exploitation by nontroglobite species? Acta Oecologica, 55: 29-35. http://dx.doi.org/10.1016/j.actao.2013.11.003

Milner E., 2013 - Cave spiders in the London area. Newsletter of the British Arachnological Society, 126: 18-20.

Nentwig W., Blick T., Gloor D, Hänggi A. \& Kropf C., 2014 - Araneae, Spiders of Europe, Version 02.2014. Universität Bern, online at: http://www.araneae. unibe.ch.

Novak T., 2005 - Terrestrial fauna from cavities in northern and central Slovenia, and a review of systematically ecologically investigated cavities. Acta Carsologica, 34: 169-210.

Novak T., Tkvac T., Kuntner M., Arnett E.A., Delakorda S.L., Perc M. \& Janžekovič F. 2010 - Niche partitioning in orbweaving spider Meta menardi and Metellina merianae (Tetragnathidae). Acta Oecologica, 36: 522-529. http://dx.doi.org/10.1016/j.actao.2010.07.005

Novak T., Perc M., Lipovsek S. \& Janžekovič F., 2012 Duality of terrestrial subterranean fauna. International Journal of Speleology, 41 (2): 181-188. http://dx.doi.org/10.5038/1827-806X.41.2.5

Nyffler M. \& Symondson W.O.C., 2001 - Spiders and harvestmen as gastropod predators. Ecological Entomology, 26: 617-628.

http://dx.doi.org/10.1046/j.1365-2311.2001.00365.x

Pastorelli C. \& Laghi P., 2006 - Predation of Speleomantes italicus (Amphibia: Caudata: Plethodontidae) by Meta menardi (Arachnida: Araneae: Metidae). Atti del $6^{\circ}$ Congresso Nazionale della Società Herpetologica Italica (Roma, 27.IX-1.X.2006): 45-47.

Pennington B.J., 1979 - The colour patterns of diurnal Meta menardi (Latreille). Bulletin of the British Arachnological Society, 4 (9): 392-393.

Platnick N. I., 2014 - The World Spider Catalog, version 14.5. American Museum of Natural History, New York, online at http:/ / research.amnh.org.

Pőtzsch J., 1966 - Notizen zur Ernahrung und Lebensweise von Meta menardi Latr. (Araneae; Araneidae). Abhandlungen und Berichte des Naturk unde museums Görlitz, 41 (10): 101-122.

Prous X., Ferreira R.S. \& Martins R.P., 2004 - Ecotone delimitation: Epigean-hypogean transition in cave ecosystems. Austral Ecology, 29: 374-382. http://dx.doi.org/10.1111/j.1442-9993.2004.01373.x

$\mathrm{R}$ Development Core Team, 2013 - R: A language and environment for statistical computing. R Foundation for Statistical Computing, Vienna, Austria. http://www.R-project.org/.

Ribera C., 1978 - Contribution à la Connaissance de la faune favernicole du nordest de 1'Espagne: le genre Meta. Proceedings of the $7^{\text {th }}$ International Congress of Arachnology (Exeter, 1977), Symposium 2001 Society of London, 42: 353-358. 
Růžička V., 1990 - The spiders of stony debris. Acta Zoologica Fennica, 190: 333-337.

Růžička V., 1999 - The first steps in subterranean evolution of spiders (Araneae) in Central Europe. Journal of Natural History, 33: 255-265.

Růžička V. \& Klimeš L., 2005 - Spider (Araneae) communities of scree slopes in the Czech Republic. Journal of Arachnology, 33: 280-289. http://dx.doi.org/10.1636/04-44.1

Sella R. \& Lana E., 2005 - Cavita (minori...?) del torinese. Ed. Io., 17 (5).

Sket B., 2008 - Can we agree on an ecological classification of subterranean animals? Journal of Natural History, 42: $1549-1563$. http://dx.doi.org/10.1080/00222930801995762

Sindaco R., Savoldelli P. \& Selvaggi A., 2009 - La Rete Natura 2000 in Piemonte. I Siti di Importanza Comunitaria. Regione Piemonte, 575 p.

Slay E.M., Fong W.D. \& Kottmayer D.M., 2009 - Meta ovalis (Araneae: Tetragnathidae) observed preying on a troglobiotic milliped, Causeyella (Chordeumatida: Trichopetalidae). Speleobiology Notes, 1: 3-5.

Smithers P., 1995 - Some observations on the distribution of Meta menardi (Latreille) in disused mines in SW Devon. Newsletter of the British Arachnological Society, 73: 6.

Smithers P., 1996 - Observations on prey of the cave spider Meta menardi (Latreille, 1804) in South Devon. Newsletter of the British Arachnological Society, 77: 12-14.

Smithers P., 2004 - Myriapods as Prey of the Cave Spider Meta menardi. Bulletin of the British Myriapod Group and Isopoda group, 20: 17-19.

Smithers P., 2005a - The diet of the cave spider Meta menardi (Latreille 1804) (Araneae, Tetragnathidae). Journal of Arachnology, 33: 243-246.

http://dx.doi.org/10.1636/CT-05-2.1

Smithers P., 2005b - The early life history and dispersal of the cave spider Meta menardi (Latreille, 1804) (Araneae: Tetragnathidae). - Bulletin of the British Arachnological Society, 13(6): 213-216.
Smithers P. \& Smith F.M., 1998 - Observations on the behaviour of second instars of the cave spider Meta menardi (Latreille, 1804). Newsletter of the British Arachnological Society, 81: 4-5.

Strinati P., 1966 - Faune cavernicole de la Suisse. Annales de Spéléologie, Moulis, 21 (1): 5-268, (2): 357-571.

Tatole A., 2005 - On the biogeography of Romanian spiders (Araneae). Acta Zoologica Bulgarica, 1: 281-285.

Tercafs R., 1972 - Biométrie spatiale dans l'écosystéme souterraine: repartition du Meta menardi Latr. (Argiopidae). International Journal of Speleology, 4: 351-355.

Tobin W.B., Hutchins B.T. \& Schwartz F.B., 2013 - Spatial and temporal changes in invertebrate assemblage structure from the entrance to deep-cave zone of a temperate marble cave. International Journal of Speleology, 42 (3): 203-214.

http://dx.doi.org/10.5038/1827-806X.42.3.4

Vadell M., 2003 - Fauna invertebrada de las cavidades del Barranc de sa Coma del Mal Pas (Palma-Calvià). Endins, 25: 107-116.

Väisänen R., 1983 - The cave spider Meta menardi (Araneidae) new to Finland. Memoranda Societatis pro Fauna et Flora Fennica, 59: 141-143.

Yoder J.A., Christensen S.B., Croxall J.T., Tank L.J. \& Hobbs III H.B., 2010 - The pheromone of the cave cricket, Hadenoecus cumberlandicus, causes cricket aggregation but does not attract the co-distributed predatory spider, Meta ovalis. Journal of Insect Science, 10 (47): 1-10. http://dx.doi.org/10.1673/031.010.4701

Zuur A.F., Ieno E.N. \& Elphick S.C., 2010 - A protocol for data exploration to avoid common statistical problem. Methods in Ecology and Evolution, 1: 3-14. http://dx.doi.org/10.1111/j.2041-210X.2009.00001.x

Zuur A.F., Ieno E.N., Walker N.J., Savaliev A.A. \& Smith G.M., 2009 - Mixed effect models and extensions in ecology with R. Ed. Springer, Berlin, 574 p. 